Navigation Physics 1(2) (2019)
Navigation Physics
Journal of Physics Education

\title{
Graphic User Interface (GUI) untuk Materi Dinamika Gerak Sistem Katrol Berbasis Matlab
}

\author{
Alpi Mahisha Nugraha ${ }^{1^{*}}$ \\ ${ }^{1}$ Informatika, Fakultas Teknik dan Ilmu Komputer, Universitas Indraprasta PGRI \\ * E-mail: alpimahisha.nugraha@unindra.ac.id
}

\begin{tabular}{|c|c|}
\hline Info Artikel & Abstract \\
\hline $\begin{array}{l}\text { Sejarah Artikel: } \\
\text { Diterima Oktober } 2019 \\
\text { Disetujui November } 2019 \\
\text { Dipublikasikan Desember } 2019\end{array}$ & $\begin{array}{l}\text { Learning physics will be less optimal if the teacher teaches based on } \\
\text { the text book. Other alternative media are needed to increase the } \\
\text { student interesting in learning and make the student can studies } \\
\text { easier. Especially fundamental chapter such as the dynamics of }\end{array}$ \\
\hline $\begin{array}{l}\text { Keywords: } \\
\text { Dynamic, Pulley system, GUI, Matlab }\end{array}$ & $\begin{array}{l}\text { motion, like pulley sytems. Because in that problems, involves both } \\
\text { of the dynamics in translation and rotational motion. Using of } \\
\text { Matlab-based on Graphic User Interface (GUI) is expected to } \\
\text { increase student's interesting and understanding of the problems in } \\
\text { pulley system. Because students just only enter the required input } \\
\text { datas and adjust the desired system conditions to calculate the } \\
\text { quantities asked for that problem. Furthermore, the designed GUI } \\
\text { can present a brief and concise explanation with easily language to } \\
\text { understand by students about the phenomenon and students can } \\
\text { also see the formula used in the pulley system problem. }\end{array}$ \\
\hline
\end{tabular}

How to Cite: Nugraha, A.M. (2019). Graphic User Interface (GUI) untuk Materi Dinamika Gerak Sistem Katrol Berbasis Matlab, Navigation Physics, 1(2): 51-58.

\section{PENDAHULUAN}

Dinamika gerak merupakan bagian rumpun ilmu fisika yang berfokus pada gerak sustu benda dengan memperdulikan penyebab geraknya. Penyebab gerak benda adalah gaya, dan besaran gaya ini terangkum dalam suatu konsep yang memenuhi Hukum Newton. Gaya yang memiliki simbol F, diambil dari kata Force yang berarti paksaan atau tarikan, sedangkan satuan gaya adalah Newton diambil dari penemunya yakni Isaac Newton. Hukum Newton terdiri dari tiga buah hukum fundamental. Ketiga hukum ini sampai saat ini yang dapat menjelaskan fenomena pada sistem gerak benda non relativistik. Persoalan dinamika dan kinematika gerak umumnya merupakan gerbang awal dari persoalan fisika yang dipelajari di sekolah. Beberapa penelitian dilakukan untuk menciptakan alternatif media pembelajaran agar siswa lebih tertarik dan lebih mudah untuk memahami konsep dinamika gerak.

Salah satunya adalah penerapan dengan pengembangan perangkat pembelajaran dengan menggunakan model plomp yang diterapkan di kelas X (Kusnaeni, 2017) agar minat belajar siswa dan penyampaian materi fisika maksimal. Bahkan, alternatif pendekatan lain juga dapat digunakan untuk mendukung konsep Hukum Newton seperti penurunan persamaan gerak benda menggunakan EulerLagrange yang diterapkan pada pesawat atwood (Ariska, 2019). Tujuannya adalah agar siswa memahami seberapa fundamentalnya Hukum Newton dalam menganalisa fenomena gerak benda. Materi dinamika gerak pun umunya terbagi menjadi gerak lurus, gerak rotasi, dan kombinasi antara gerak lurus dan gerak rotasi tergantung pada kasus soal yang dihadapi siswa.

Pada dinamika gerak lurus bermacam-macam pengembangan sudah dilakukan seperti pengembangan alat peraga berbasis lingkungan untuk meninjau dinamika gerak sebuah partikel (Isnanto, 2014) yang diharapkan akan berpengaruh pada kemampuan psikomotor siswa. Cara-cara inilah yang akan menjadi nilai tambah dalam penyampaian materi sehingga siswa dapat maksimal memehami konsep dari Hukum Newton itu sendiri. Selain itu untuk dinamika gerak rotasi juga terdapat banyak 
pengembangan terutama dalam materi kesetimbangan benda tegar yang bertanggung jawab terhadap keadaan kesetimbangan benda atau inersia benda (Zulirfan, 2011). Tidak hanya itu, terdapat juga pengembangan interaktif berupa interaktif e-megazine dalam memahami materi dinamika rotasi (Nurjanah, 2014). Pengembangan-pengembangan ini dilakukan untuk meningkatkan minat dan pemahaman siswa terhadap persoalan dinamika gerak benda.

Persoalan dinamika gerak merupakan persoalan yang dianggap cukup sulit untuk kebanyakan siswa, bahkan kendala ini juga ditemukan pada kalangan mahasiswa sehingga diperlukan modul pembelajaran yang menarik dan efektif (Santoso, 2014: 39-45). Berdasarkan hal tersebut diperlukan aplikasi yang efisien dan efektif yang dapat digunakan siswa dalam memahami persoalan dinamika gerak baik gerak lurus ataupun gerak rotasi. Salah satu aplikasi tersebut dapat diterapkan berupa Graphic User Interface (GUI) berbasis Matlab, penggunaan matlab mempermudah peneliti untuk merancang media alternatif berupa GUI yang friendly sehingga siswa tidak perlu lagi bulak-balik membaca buku panduan untuk mengerjakan soal, siswa cukup memasukkan input yang dibutuhkan dan menyesuaikannya dengan kasus yang diinginkan (Nugraha, 2019 : 6-11).

GUI yang friendly pun menjadi nilai tambah karena penggunaannya yang mudah sehingga siswa tidak akan kesulitan saat menggunakan aplikasi. Karena cakupan dinamika gerak sangatlah luas untuk membatasinya aplikasi akan dirancang untuk menyelesaiakan persoalan berupa sistem gerak pada katrol seperti pada Gambar 1. Persoalan gerak sistem katrol merupakan gabungan antara dinamika gerak lurus dan rotasi. Jika massa katrol diabaikan maka katrol dianggap tidak berputar sehingga hanya dinamika gerak lurus sajalah yang berlaku, berbeda jika massa katrol tidak diabaikan yang berarti katrol berputar sehingga selain dinamika gerak lurus yang bertanggung jawab, terdapat juga dinamika gerak rotasi dalam menjelaskan fenomena tersebut. Persoalan seperti inilah yang sering membuat siswa menjadi

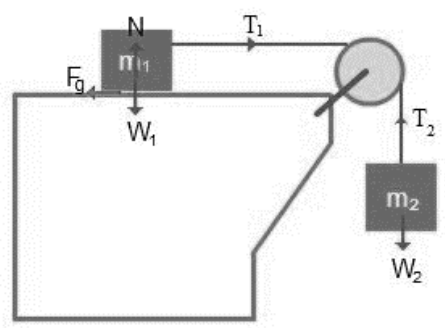

Gambar 1. Persoalan Dinamika Gerak Sistem katrol

kebingungan, oleh karena itu penggunaan GUI dapat membuat siswa lebih memahami persoalan tersebut.

\section{METODE PENELITIAN}

Metode penelitian yang dilakukan terbagi menjadi studi pustaka, penurunan persamaan gerak secara numerik untuk nilai percepatan dan tegangan tali, pembuatan GUI, dan analisis sistem fisis.

\section{A. Studi Pustaka}

Studi pustaka dilakukan untuk memahami konsep dinamika gerak pada sistem katrol agar mempermudah perancangan GUI yang sesuai dan friendly. Studi pustaka juga membuat peneliti dapat mengembangkan metode yang sudah ada atau membandingkan dengan metode lain dengan permasalahan yang sama yakni dinamika gerak pada sistem katrol agar mendapat banyak sudut pandang dalam menyelesaikan permasalahan.

\section{B. Penurunan persamaan gerak}

Penurunan rumus untuk mencari nilai percepatan (a), tegangan tali pada benda $m_{1}\left(T_{1}\right)$, dan tegangan tali pada benda $\mathrm{m}_{2}\left(\mathrm{~T}_{2}\right)$ dimulai dengan menggunakan Hukum Newton (Giancolli, 1997) dan membagi sudut pandang menjadi tinjau benda $\mathrm{m}_{1}$, tindau benda $\mathrm{m}_{2}$ dan tinjau katrol dengan massa $\mathrm{m}_{\mathrm{k}}$.

- Tinjau benda $\mathrm{m}_{1}$

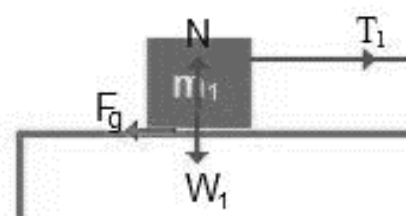

$$
\begin{aligned}
& \sum \mathrm{F}=\mathrm{m}_{1} \mathrm{a} \\
& \mathrm{T}_{1}-\mathrm{F}_{\mathrm{g}}=\mathrm{m}_{1} \mathrm{a} \\
& \mathrm{T}_{1}-\mathrm{miu} \cdot \mathrm{m}_{1} \cdot \mathrm{g}=\mathrm{m}_{1} \mathrm{a} \\
& \mathrm{T}_{1}=\mathrm{m}_{1} \mathrm{a}+\text { miu } \cdot \mathrm{m}_{1} \cdot \mathrm{g}
\end{aligned}
$$


dengan miu adalah koefisien gesek antara permukaan benda $\mathrm{m}_{2}$ dengan lantai.

- Tinjau benda $\mathrm{m}_{2}$

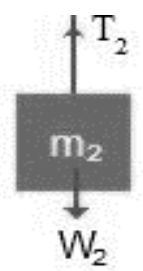

$$
\begin{gathered}
\sum \mathrm{F}=\mathrm{m}_{2} \mathrm{a} \\
\mathrm{W}_{2}-\mathrm{T}_{2}=\mathrm{m}_{2} \mathrm{a} \\
\mathrm{m}_{2} \cdot \mathrm{g}-\mathrm{T}_{2}=\mathrm{m}_{2} \mathrm{a} \\
\mathrm{T}_{2}=\mathrm{m}_{2} \cdot \mathrm{g}-\mathrm{m}_{2} \cdot \mathrm{a}
\end{gathered}
$$

Setelah diperoleh persamaan $\mathrm{T}_{1}$ dan $\mathrm{T}_{2}$, selanjutnya tinjau katrol. Anggapan awal katrol dengan jari-jari $\mathrm{R}$ akan berputar yang disebabkan karena adanya perbedaan antara $T_{1}$ dan $T_{2}$ (Tipler, 2004). Sehingga persamaan yang digunakan dimulai dengan persamaan, $\Sigma \tau=\mathrm{I} \alpha$ dengan $\tau$ adalah torsi, I adalah inersia dan $\alpha$ adalah percepatan sudut dalam satuan internasional. Umumnya I pada katrol bernilai $1 / 2 \mathrm{~m}_{\mathrm{k}} \mathrm{R}^{2}$, karena katrol dianggap sebuah cakram sedangkan $\alpha=\mathrm{a} / \mathrm{R}$, dengan a adalah percepatan sistem. Oleh karena itu diperoleh persamaan:

$$
\begin{gathered}
\Sigma \tau=\mathrm{I} \alpha \\
\Sigma \tau=0.5 \mathrm{~m}_{k} \mathrm{R}^{2} \frac{\mathrm{a}}{R} \\
\left(T_{2}-T_{1}\right) \mathrm{R}=0.5 \mathrm{~m}_{k} \mathrm{R}^{2} \frac{\mathrm{a}}{R} \\
\left(T_{2}-T_{1}\right)=0.5 \mathrm{~m}_{k} \mathrm{a}
\end{gathered}
$$

Subtitusikan persamaan (1) dan (2) ke dalam persamaan (3) sehingga diperoleh persamaan

$$
a=\frac{\mathrm{m}_{2} \cdot \mathrm{g}-\mathrm{miu} \cdot \mathrm{m}_{1} \cdot \mathrm{g}}{m_{1}+m_{2}+0.5 m_{k}}
$$

Persamaan (4) inilah yang menjadi faktor utama dalam menentukan pergerakan sistem. Oleh karena itu diperlukan pengecekan sistem bergerak atau tidak. Benda akan bergerak jika $\mathrm{m}_{2} \cdot \mathrm{g}>$ miu . $m_{1}$.g, dan jika benda bergerak untu menghitung $T_{1}$ dan $T_{2}$ digunakan persamaan (1) dan persamaan (2). Namun nilai miu dan $m_{k}$ tergantung pada kasus yang terjadi. Jika lantai licin maka miu bernilai nol dan bernilai $0<\operatorname{miu}<1$ untuk lantai kasar. Sedangkan $m_{k}$ bernilai nol jika massa katrol diabaikan dan jika massa katrol tidak diabaikan maka $m_{k} \neq 0$.

\section{Pembuatan GUI}

Perhitungan analisis numerik pada persamaan a, $T_{1}$, dan $T_{2}$ akan dijadikan sebagai persamaan matematis yang disajikan menggunakan bahasa pemrograman MATLAB sesuai dengan persamaan (1), persamaan (2) dan persamaan (4). Besaran input yang diperlukan adalah massa benda $\mathrm{m}_{1}$, massa benda $\mathrm{m}_{2}$, miu atau koefisien gesek, dan massa katrol $\mathrm{m}_{\mathrm{k}}$. GUI yang dibuat akan mempunyai lima perhitungan sesuai dengan lima kasus yang mungkin terjadi untuk persoalan dinamika katrol ini. Adapun kasus-kasus tersebut adalah:

1. Kasus 1 , kasus dimana $\mathrm{m}_{2} \cdot \mathrm{g}<\mathrm{miu} \cdot \mathrm{m}_{1} \cdot \mathrm{g}$ yang akan berakibat sistem tidak akan bergerak karena berat benda $\mathrm{m}_{2}$ tidak cukup besar melawan gaya gesek yang dialami benda $\mathrm{m}_{1}$.

2. Kasus 2, kasus dengan kondisi lantai licin dan massa katrol diabaikan, yang akan berakibat miu dan $\mathrm{m}_{\mathrm{k}}$ bernilai nol dan $\mathrm{T}_{1}=\mathrm{T}_{2}$.

3. Kasus 3, kasus dengan kondisi lantai kasar dan massa katrol diabaikan, ketika lantai kasar maka nilai miu menjadi input yang akan diisi oleh pengguna GUI. Namun karena katrol tetap diabaikan maka $\mathrm{T}_{1}=\mathrm{T}_{2}$.

4. Kasus 4, kasus dengan kondisi lantai licin namun massa katrol tidak diabaikan sehingga besar $\mathrm{m}_{\mathrm{k}}$ akan menjadi input yang diisi oleh pengguna GUI. Karena lantai licin maka miu bernilai nol, sedangkan $\mathrm{T}_{1} \neq \mathrm{T}_{2}$ karena saat massa katrol tidak diabaikan maka katrol berputar akibat perbedaan $\mathrm{T}_{1}$ dan $\mathrm{T}_{2}$.

5. Kasus 5 , kasus dengan lantai kasar dan massa katrol tidak diabaikan, maka nilai miu dan $\mathrm{m}_{\mathrm{k}}$ akan menjadi input, dan sama halnya dengan kasus 4 maka $T_{1} \neq T_{2}$ 
Adapun algoritma atau diagram alir dari GUI yang akan dibuat sesuai dengan Gambar 2.

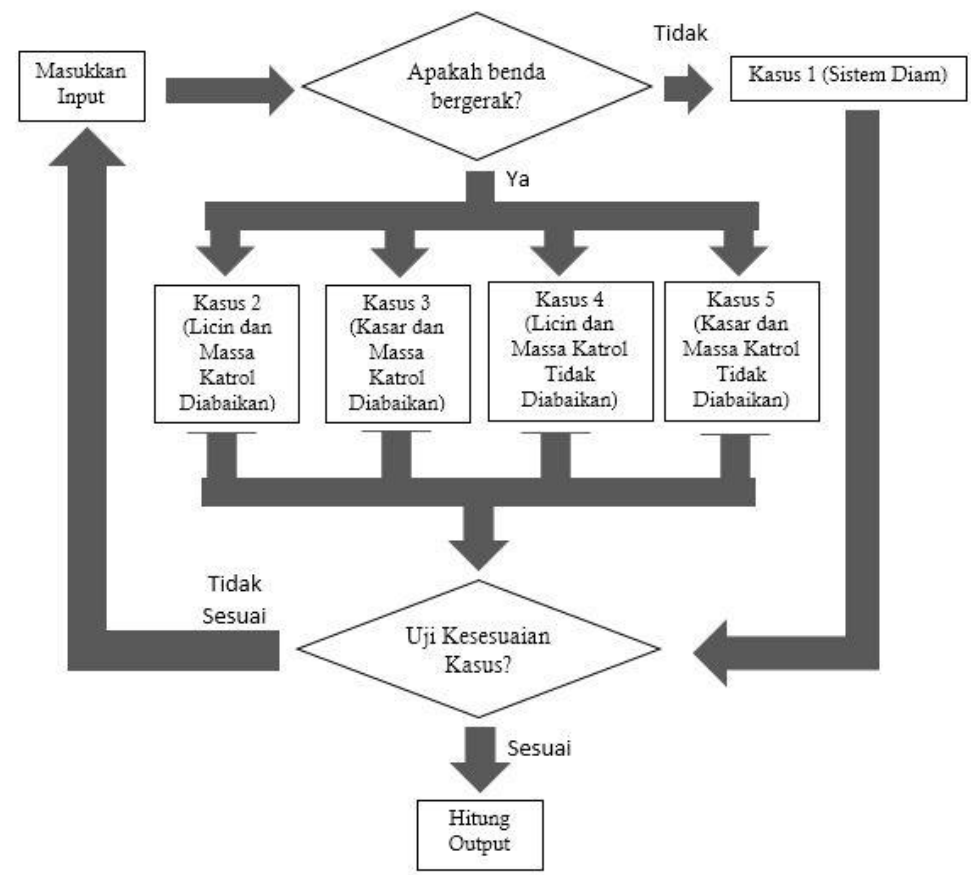

Gambar 2. Diagram alir atau algoritma GUI dinamika sistem gerak katrol (Sumber: Peneliti)

GUI akan dirancang untuk dapat menyelesaikan lima macam kasus yang terjadi. Agar siswa atau mahasiswa lebih mudah menggunakan perhitungan tersebut, input dan output dalam perhitungan akan ditampilkan dalam bentuk GUI yang friendly.

\section{Analisis Sistem Fisis}

Tahap terakhir dari metode penelitian adalah menganalisis sistem fisis dari hasil perhitungan pada GUI. Hal ini dilakukan untuk mengurangi kesalahan konsep dan kesusuaiaan hasil perhitungan dengan fenomena yang terjadi.

\section{HASIL DAN PEMBAHASAN}

Penggunaan GUI sebagai media pembelajaran materi dinamika gerak diharapkan menjadi alternatif yang efektif untuk meningkatkan pemahaman siswa, perancangan yang friendly membuat siswa hanya perlu memasukkan besaran-besaran input yang dibutuhkan yakni massa benda $\mathrm{m}_{1}$, massa benda $\mathrm{m}_{2}$, koefisien gesek (miu) jika pilihan lantai kasar dan massa katrol $\mathrm{mk}$ jika pilihan massa katrol $\mathrm{m}_{\mathrm{k}}$ tidak diabaikan. Adapun tampilan GUI yang dirancang terlihat pada Gambar 3. Siswa hanya perlu

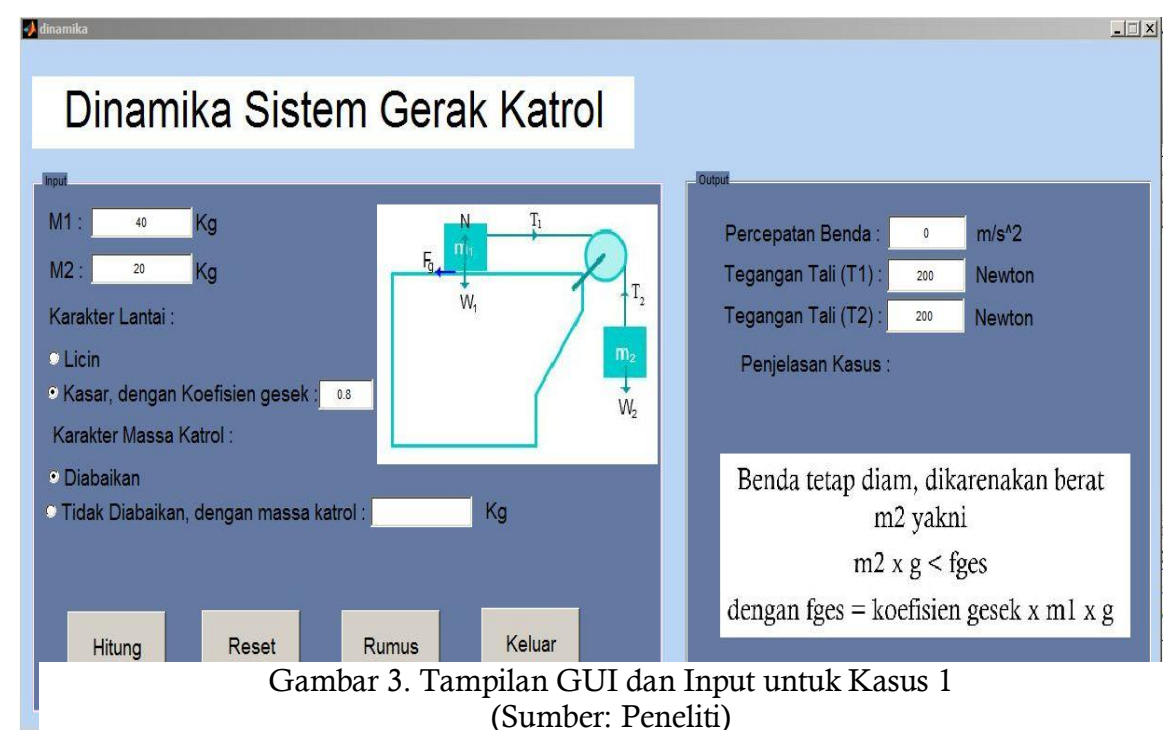


memasukkan input di bagian panel input dan menyesuaikan keadaan sistem yang diinginkan dengan mengatur radiobutton yang disediakan.

Pada Gambar 3 menunjukkan kasus 1 dimana sistem katrol tidak akan bergerak atau diam jika input berupa $\mathrm{m}_{1}=40 \mathrm{~kg}, \mathrm{~m}_{2}=20 \mathrm{~kg}$ dan lantai kasar dengan koefisien gesek bernilai 0.8 . Hal ini dijelaskan juga pada sudut kanan bawah GUI mengapa sistem katrol diam. Umumnya siswa mengalami kesalahan konsep untuk kasus ini, karena siswa jika langsung menggunakan persamaan (4) maka nilai percepatan a yang dihasilkan akan bernilai negatif, dan dengan hasil seperti ini siswa biasanya menganggap bahwa benda $m_{1}$ bergerak ke sebelah kiri dan benda $m_{2}$ bergerak ke atas tertarik oleh gaya gesek yang dialami benda $\mathrm{m}_{1}$. Pemahaman seperti inilah yang menjadi kesalahan dalam memahami konsep dinamika, jadi tidak semua sistem ketika diberi gaya akan bergerak, benda bergerak bergantung pada besar gaya berat $\mathrm{m}_{2}$ yang dapat melawan gaya gesek maksimal $\mathrm{m}_{1}$ atau tidak. Lain ceritanya jika kondisi lantai licin.

Pada kondisi lantai licin, meskipun massa benda $\mathrm{m}_{2}$ sangat kecil dibandingkan dengan massa benda $\mathrm{m}_{1}$, maka sistem akan tetap bergerak ke bawah. Karena tidak ada yang menghambat berat $\mathrm{m}_{2}$ untuk menggerakkan sistem. Penjelasan seperti ini juga akan ditemui siswa pada tampilan GUI jika input yang dimasukkan sesuai dengan kemungkinak kasus yang terjadi. Andaipun siswa mengalami kesalahan dlaam memasukan inputan akan terdapat warning dialog untuk mengingatkan siswa untuk mengisi besaran yang diperlukan.

Berbeda dengan kasus 5 yakni ketika lantai kasar dan massa katrol tidak diabaikan. Hal ini berarti bahwa yang berlaku pada sistem tidak hanya dinamika gerak lurus saja melainkan berlaku juga dinamika gerak rotasi yang dapat dilihat pada Gambar 4 dengan input $\mathrm{m}_{1}=40 \mathrm{~kg}, \mathrm{~m}_{2}=20 \mathrm{~kg}$, kondisi lantai kasar dengan koefisien gesek miu $=0.2$ dan massa katrol tidak diabaikan dengan massa katrol $\mathrm{m}_{\mathrm{k}}=10 \mathrm{~kg}$. Penjelasan pda GUI pun akan berbeda tiap kasusnya, dengan penjelasan tambahan ini diharapkan siswa akan lebih memahami konsep dinamika gerak sistem katrol.

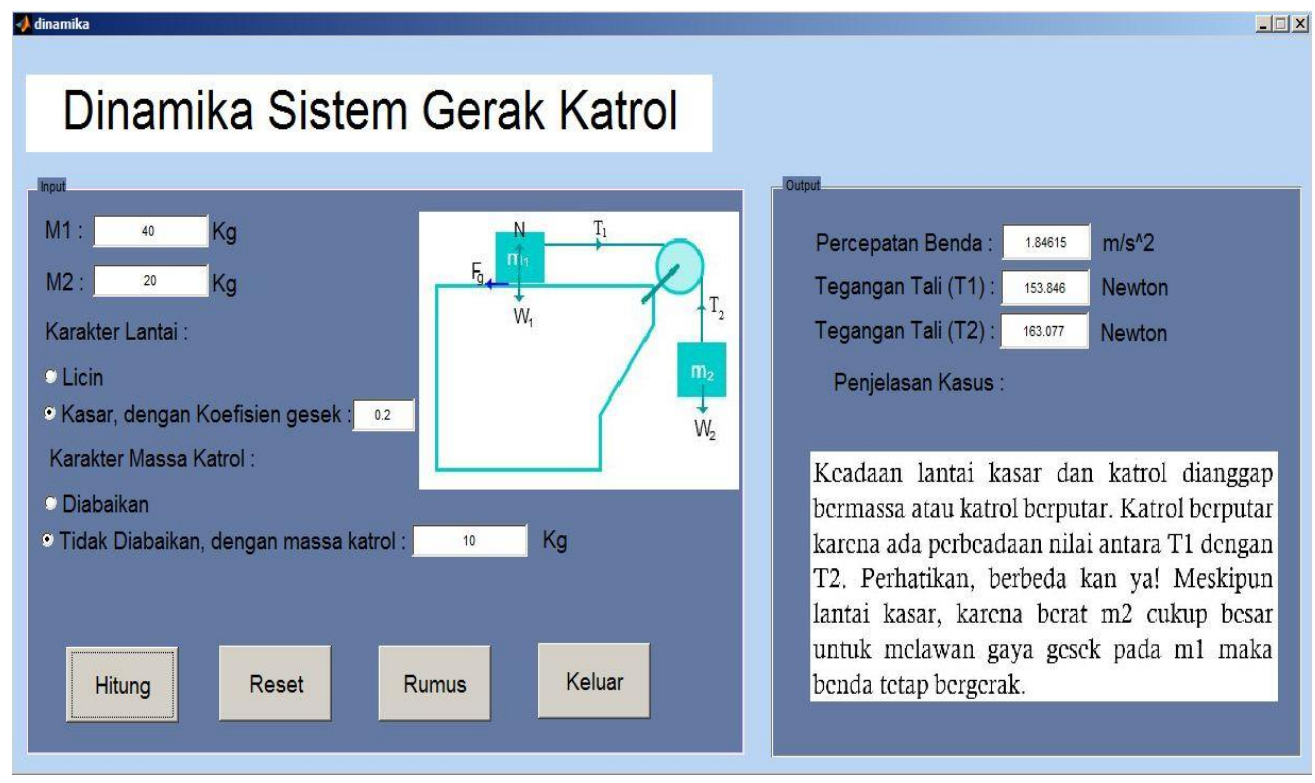

Gambar 4. Tampilan GUI dan Input Kasus 5 (Sumber: Peneliti)

Perbandingan hasil perhitungan untuk masing-masing kasus dapat dilihat pada Tabel 1. Output yang dihitung adalah percepatan a sesuai dengan persamaan (4), besar tegangan tali pada $\mathrm{m}_{1}$ sesuai persamaan (1) dan besar tegangan tali pada $\mathrm{m}_{2}$ sesuai persamaan (2). Pada kasus satu digunakan input $\mathrm{m}_{1}=40 \mathrm{~kg}, \mathrm{~m}_{2}=20 \mathrm{~kg}$ dan miu 0.8 hal ini dilakukan karena agar benda diam maka berat $\mathrm{m}_{2}$ harus lebih kecil dari gaya gesek yang dialami benda. Pada kasus ini, besar percepatan yang dihasilkan otomatis bernilai nol karena sistem diam. Pada saat benda diam maka besar $\mathrm{T}_{1}$ dan $\mathrm{T}_{2}$ adalah sama sehingga katrol tidak berputar sesuai dengan data yang dihasilkan pada Tabel 1. 
Pada kasus 2 sampai dengan kasus 5 dipergunakan input $\mathrm{m}_{1}=40 \mathrm{~kg}, \mathrm{~m}_{2}=20 \mathrm{~kg}$, miu 0.8 , dan $\mathrm{m}_{\mathrm{k}}=10 \mathrm{~kg}$ dan penyesuaian pada radiobutton. Pada kasus massa katrol diabaikan seperti pada kasus 2 dan kasus 3 maka nilai $T_{1}$ dan $T_{2}$ sama. Namun menariknya pada kasus 3 dengan lantai kasar ternyata besar tegangan talinya lebih besar. Informasi ini menunjukkan bahwa tali akan lebih tegang saat pada $\mathrm{m}_{1}$ terdapat penghambat gaya yaitu gaya gesek yang dialami benda $\mathrm{m}_{1}$. Namun besar tegangan tali akan lebih mengecil lagi jika massa katrol tidak diabaikan yang terlihat pada kasus 4 dan kasus 5, karena katrol mengalami perputaran akibat perbedaan atara $\mathrm{T} 1$ dan $\mathrm{T} 2$, maka katrol juga berkontribusi terhadap penjalaran usaha dan energi pada sistem sehingga besar tegangan tali yang dirasakan benda $\mathrm{m}_{1}$ ataupun benda $\mathrm{m}_{2}$ lebih kecil dibandingkan saat massa katrol diabaikan atau katrol dianggap tidak berputar.

Tabel 1. Perbandingan hasil perhitungan untuk masing-masing kasus

\begin{tabular}{lccccc}
\hline \multicolumn{1}{c}{ Besaran Output } & Kasus 1 & Kasus 2 & Kasus 3 & Kasus 4 & Kasus 5 \\
\hline Percepatan $\left(\mathrm{ms}^{-2}\right)$ & 0 & 3.33333 & 2 & 3.07692 & 1.84615 \\
Tegangan tali $\mathrm{m}_{1}(\mathrm{~N})$ & 200 & 133.333 & 160 & 123.077 & 153.846 \\
Tegangan tali $\mathrm{m}_{2}(\mathrm{~N})$ & 200 & 133.333 & 160 & 138.462 & 163.077 \\
\hline
\end{tabular}

\section{PENUTUP}

Penggunaan GUI dapat menunjukkan bahwa nilai percepatan dan tegangan tali pada sistem katrol ditentukan oleh kondisi lantai dan karakter katrol itu sendiri. Selain besaran input yang diperlukan pemahaman akan kondisi persoalan diperlukan dalam menyelesaikan soal sistem katrol ini. GUI yang digunakan dapat menjadi alternatif pembelajaran agar siswa semakin memahami materi seperti adanya perbedaan tegangan tali yang dirasakan benda $m_{1}$ dan $m_{2}$ saat katrol berputar, pengaruhnya kekasaran lantai terhadap besar percepatan yang dialami sistem sampai fenomena unik jika keadaan lantai licin, dimana meskipun benda $\mathrm{m}_{2}$ adalah kelereng yang bermassa sangat kecil dan $\mathrm{m}_{1}$ adalah gajah yang bermassa besar, maka sistem tetap akan bergerak.

Penggunaan GUI pada persoalan dinamika gerak sistem katrol akan lebih efektif jika disertakan gambaran visual mengenai gerak sistem yang sesuai dengan input yang digunakan. Beragam jenis persoalan katrol memiliki persamaan yang berbeda untuk sistem yang lain meskipun menggunakan konsep yang sama, namun diperlukan koleksi persoalan sistem katrol yang lain sehingga siswa memilki alternatif jenis soal untuk memehami konsep dinamika gerak.

\section{DAFTAR PUSTAKA}

Ariska, Melly. (2019). Penyelesaian Dinamika Pesawat Atwood dengan Menggunakan Persamaan Euler-Lagrange sebagai Alternatif Persamaan Newton pada Fisika SMA. Jurnal Inovasi dan Pembelajaran Fisika. Vol 6, No 1.

Giancoli, Douglas. (1997). Fisika 1. Prentice Hall. Terjemahan: Erlangga-jakarta.

Isnanto, Agus Slamet. (2014). Pengaruh Penggunaan Alat Peraga Berbasis Lingkungan (APBL) pada Materi Dinamika Partikel terhadap Kemampuan Psikomotor P1 Peserta Didik Kelas X SMA Negeri 1 Kutowinangun. Radiasi: Jurnal Berkala Pendidikan Fisika. Vol 4, No 1.

Kusnaeni. (2017). Pengembangan Perangkat Pembelajaran Fisika Kelas X dengan Model Plomp di SMA Negeri 5 Palu. Mitra Sains. Vol 5, No 1.

Nugraha, Alpi Mahisha, dkk. (2019). Blast-off Simulation sebagai Alternatif Media Pembelajaran Siswa dalam Mempelajari Mekanika Gerak Roket Berbasis Matlab. Navigation Physics: Journal of Physics Education. Vol 1, No 1, Hal: 6-11.

Nurjanah, Jalilah Rahmastuti, dkk. (2014). Pengembangan Media Pembelajaran Interaktif E-Megazine pada Materi Pokok Dinamika Rotasi untuk SMA keals XI. Jurnal Materi dan Pembelajaran Fisika (JMPF). Vol 4, No 1.

Santoso, Emie, dkk. (2014). Metode Evaluasi Praktikum Mahasiswa untuk Matakuliah Praktikum Fisika. Jurnal Pendidikan Profesional. Vol 3, No 2, Hal: 39-45. 
Tipler, Paul A. (2004). Physics for scientist and engineer 5th edition. W.H.Freeman and Company Newyork.

Zulirfan, dkk. (2011). Pengembangan Perangkat Percobaan Momen Inersia dan Keseimbangan Benda Tegar sebagai Media Pembelajaran Fisika SMA. Jurnal Pendidikan: Journal of Education. Vol 2, No 2. 
Alpi Mahisha Nugraha / Navigation Physics 1 (2) (2019) Graphic User Interface (GUI) untuk ... 